\title{
Migration Bottlenecks, Climate, and the Conservation of Pleistocene Relicts in Central Asia
}

\author{
Joel Berger*, ${ }^{, 1,2}$, Kim Murray Berger ${ }^{2}$, Scott Bergen ${ }^{3}$, Bayarbaatar Buuveibaatar ${ }^{4}$, Amanda Fine ${ }^{5}$, \\ Badamjav Lkhagvasuren ${ }^{4}$, Julie K. Young ${ }^{2}$ and Peter Zahler ${ }^{3}$
}

${ }^{1}$ Division of Biological Sciences and WCS - Northern Rockies Field Office, University of Montana, Missoula, MT 59812,
USA; ${ }^{2}$ Wildlife Conservation Society, Northern Rockies Field Office, University of Montana, Missoula, MT 59812, USA;
${ }^{3}$ Wildlife Conservation Society, Bronx Zoo, Bronx, NY 10460; ${ }^{4}$ Institute of Biology, Mongolian Academy of Sciences,
Ulaanbaatar-51, Mongolia; ${ }^{5}$ Wildlife Conservation Society, PO Box 485, Post Office 38 Ulaanbaatar 211238 Mongolia

Abstract: Land bridges once assured transcontinental connectivity, but climate-induced habitat loss resulted in the extinction of numerous North American large mammals. Using GPS technology on the formerly widespread but now endangered saiga in Mongolia, we identified a fine-scaled 5-km wide critical corridor, whose protection is critical for maintaining migration and meta-population structure.

The world's great overland migrations are disappearing, truncating fundamental processes that have contributed to ecosystem functioning for millennia. With more people reliant on lands that were once remote, intact habitats are now replaced by livestock, fences, and people [1]. Nevertheless, expansive grasslands and deserts in China, Mongolia, Kazakhstan, and Russia still sustain extraordinary movements between winter and summer ranges, including those of chiru (Pantholops hodgsonii), white-(Procapra gutturosa) and black-tailed (Gazella subgutturosa) gazelles, khulan (Equus hemionus), saiga (Saiga tatarica), and Bactrian camels (Camelus bactrianus) [2 - 4]. The latter three species - all recognized as endangered by the IUCN - along with mammoths, Panthera lions, and wild horses (Equus spp.) once moved between Asia and North America using the Bering Land Bridge. That conduit for inter-continental movement collapsed during the Late Pleistocene when climate changed, ocean levels rose, and the arid Mammoth Steppe of Beringea disappeared [5]. Although saiga, camels, and wild horses were dependent upon these cold-adapted xeric grasslands, such remnant Pleistocene habitats and their associated fauna currently persist in situ only in Central Asia [5].

While the Being Land Bridge once enabled connectivity across broad landscapes, today's conservation challenges are appropriately more linked to the maintenance of connectivity among population subunits, protecting corridors at a fine scale, and understanding the direct impacts of humans under an umbrella of climate change. Long-term conservation of fragmented populations requires maintenance of metapopulation structure. With the above little-known relicts restricted to Central Asia, a critical challenge has been the acquisition of knowledge, not only about migration routes, if any, but the protection of land(s) critical to sustaining movements among disjunct population segments [6].

*Address correspondence to this author at the Division of Biological Sciences and WCS - Northern Rockies Field Office, University of Montana, Missoula, MT 59812, USA; E-mail: joel.berger@mso.umt.edu
To persist, saiga have faced the long term threat of climate change and now the more immediate danger of human persecution and habitat degradation. In $<2$ decades, numbers have dropped $>95 \%$, from $>1,000,000$ to $<50,000$ [7]. Saiga are mainly hunted for their horns. While poaching since the collapse of the former Soviet Union has been the most serious proximate threat, protection for the endangered Mongolian subspecies has been hampered by a lack of knowledge about movements and locations in which to focus conservation efforts.

In migratory species such as wildebeest (Connochaetes taurinus) and caribou (Rangifer tarandus), most migrations cross wide swaths of unbroken habitat up to $30 \mathrm{kms}$ wide; only for pronghorn do movements through narrow corridors play a crucial role to diminish the probability of extirpation [8]. The differences among the above species may be more a consequence of topography rather than species-specific traits since pronghorn in some parts of the American west must funnel through narrow mountain passages. Nevertheless, data on saiga movements have been lacking and so it has generally been assumed that, like other migratory ungulates, few critical corridors have existed.

Using global positioning system (GPS) radio-collars deployed on adult female saiga, we identified a narrow corridor connecting two subpopulations north of the Altai Mountains in western Mongolia (Fig. 1). Although home ranges of individually-marked females are $3,000-4000 \mathrm{~km}^{2}$, each of four GPS-equipped animals using northern parts of the ShargynGovi depression relied on an apparent bottleneck $<5 \mathrm{kms}$ wide during north-south movements between September 2006 and August 2007. This area represents the only viable route by which animals from the Shargyn-Govi connect to the Huysiyn-Govi subpopulation, and thus maintain a metapopulation structure. The integrity of this biologically important suture of usable habitat is increasingly challenged by the primary access road connecting two major soums (towns). Although this travel path for humans is nothing more than a dirt spoor, it is used by motorcycles, trucks, and other vehi- 


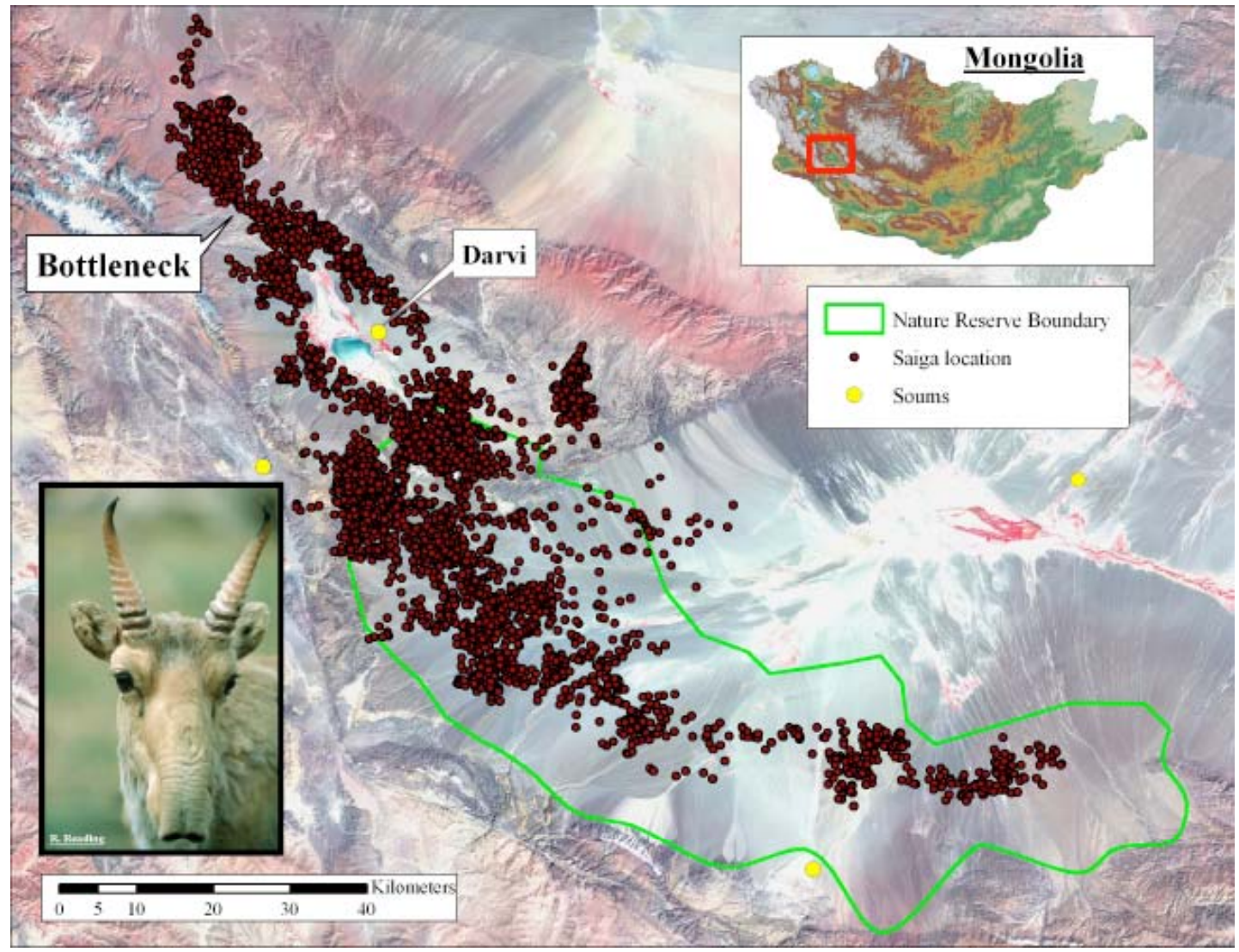

Fig. (1). GPS-locations from four female saiga near Darvi soum (town) in the Shargyn-Govi Nature Reserve, Mongolia (location indicated on map inset of Mongolia). Photo inset of male saiga, often hunted for their horns.

cles, as well as receiving extensive use by semi-nomadic herders bringing their yaks, camels, sheep, goats, and horses to pasture. If saiga are like other ungulates, they learn rapidly that disturbance by humans comes in many forms [9]. Irrespective of learning ability, if saiga meta-population structure is to persist, protection of this corridor appears urgent given burgeoning populations OF saiga.

Like other species of steppes and deserts, saiga have avoided extinction by the continental tracking of climateinduced habitat shifts associated with broad-based metapopulation structure. Bactrian camels, the re-introduced tahki (Przewalski horses, Equus caballus prsewalskii), and hemionids like khulans - all with similar morpho-types - once occurred in the Yukon and Northern Alaska and are among the fortunate few to persist in Central Asia. Given uncertainty about site-specific effects of global climate change and how and where species might persist, prudent conservation strategies must account for widespread movements of highly mobile species.

Our findings on Mongolian saiga detail the relevance of protecting geographical bottlenecks to ensure connectivity between sub-populations. If conservation is to succeed in Central Asia, on-the-ground approaches involving local peo- ple in consort with government agencies must play increasingly important roles beyond those of large scale scientific inquiry of climate and species re-distributions. Otherwise, the last chance to see these relicts will soon be within the confines of zoological parks.

\section{REFERENCES}

[1] Wilcove D. No way home: the decline of the world's great migrations. Covello: Island Press 2007.

[2] Schaller GB. Wildlife of the Tibetan steppe. Chicago: University of Chicago Press 1998.

[3] Berger J The longest mile: How to sustain long distance migration in mammals. Cons Biol 2004; 18: 320-2.

[4] Olson KA, Fuller TK, Schaller GB, Odonkhuu D, Murray MG. Estimating the population density of Mongolian gazelles Procapra gutturosa by driving long-distance transects. Oryx 2005; 39: 164-9.

[5] Guthrie RD. Frozen fauna of the Mammoth steppe. Chicago: University of Chicago Press 1990.

[6] Harris, RB. Wildlife conservation in China: preserving the habitat of China's wild west. Armonk: M. E. Sharpe 2008.

[7] Milner-Gulland EJ, Kholodova MV, Bekenov A, et al. Dramatic decline in saiga populations. Oryx 2001; $35: 340-5$.

[8] Berger J, Cain SL, Berger K. Connecting the dots: an invariant migration corridor links the Holocene to the present. Biol Lett 2006; 2: 528-31.

[9] Berger J. The better to eat you with: fear in wild animal societies. Chicago: University of Chicago Press, (In Press)

Received: January 29, 2008 Revised: February 25, 2008 Accepted: February 26, 2008

(C) Berger et al.; Licensee Bentham Open.

This is an open access article distributed under the terms of the Creative Commons Attribution License (http://creativecommons.org/licenses/by/2.5/), which permits unrestrictive use, distribution, and reproduction in any medium, provided the original work is properly cited. 